\title{
Effect of Different Drought Stress on Seedling Growth and Physiological Characteristics of Cenchrus pauciflorus Benth
}

\author{
Ye Jiang1, Tiange Cai ${ }^{1}$, Fengde Tang ${ }^{2}$ \\ ${ }^{1}$ College of Life Science, Liaoning University, Shenyang, China \\ ${ }^{2}$ Business School, Liaoning University, Shenyang, China \\ Email: 578614568@qq.com
}

How to cite this paper: Jiang, Y., Cai, T.G. and Tang, F.D. (2019) Effect of Different Drought Stress on Seedling Growth and Physiological Characteristics of Cenchrus pauciflorus Benth. Open Access Library Journal, 6: e5933.

https://doi.org/10.4236/oalib.1105933

Received: November 18, 2019

Accepted: December 15, 2019

Published: December 18, 2019

Copyright $\odot 2019$ by author(s) and Open Access Library Inc.

This work is licensed under the Creative Commons Attribution International License (CC BY 4.0).

http://creativecommons.org/licenses/by/4.0/

\begin{abstract}
As a kind of invasive alien plants, the Cenchrus pauciflorus Benth. is spreading in the range of sandy grassland in Liaoning, which reduced the biodiversity of grassland, and greatly affected the ecological environment of grassland. It is of great significance to understand the distribution of biomass and physiological characteristics in the management of grassland and the improvement of the ecological environment of the grassland. The experiment was conducted to study the effects of drought stress on the biomass allocation and physiological characteristics of its seedlings in different soil substrates. The results show that the effects of drought stress on sandbur seedling root, stem, leaf, spike biomass distribution and physiological characteristics of seedlings significantly in two different soil matrix, the distribution of each component of the plant biomass are peat soil > sandy soil; effects of drought stress on plant biomass allocation of two the soil quality, the specific performance of mild drought stress $>$ control group $>$ under moderate drought $>$ severe drought stress. In terms of physiological characteristics, with the deepening of drought stress and the prolongation of drought stress, the malondialdehyde content, relative leaf water content, and SOD activity of plants gradually increased, and peat soil was larger than aeolian sand soil. The analysis thinks, the physiological characteristics of two kinds of soil matrix sandbur plant components and biomass distribution of seedlings showed strong drought resistance and adaptability of the environment makes it to the poor soil diffusion growth potential.
\end{abstract}

\section{Subject Areas}

Bioengineering, Plant Science

\section{Keywords}

Cenchrus pauciflorus Benth, Drought Stress, Soil Matrix, Biomass Allocation, 
Physiological Characteristics

\section{Introduction}

Cenchrus pauciflorus Benth., a 1-year-old herb of the genus Herba, commonly known as grass dog, grasshopper, and fibrous roots distributed in $5-20 \mathrm{~cm}$ soil with sand cover. Stem cylindrical hollow, semi-skull, high $30-70 \mathrm{~cm}$, strong tillering force, leaf sword shape alternate [1]. It is distributed in Liaoning, Inner Mongolia and other places in China [2]. The Phyllostachys pubescens in Liaoning Province is mainly located on sandy grassland in Fuxin, Chaoyang and Jinzhou in northwestern Liaoning [3]. Its continuous invasion has reduced grassland biodiversity, brought considerable harm to animal husbandry production and agricultural activities, and caused economic losses. In 2008, the Institute of Agro-Environment and Sustainable Development of the Chinese Academy of Agricultural Sciences listed 22 species of agricultural alien invasive plants including Phyllostachys pubescens [4]. When plants are exposed to drought stress, physiological processes are affected to varying degrees. Arid environment is one of the important environmental factors affecting plant growth, reproduction, and fruiting. However, in recent years, the climate change caused by insufficient survival and economic development has shortened and aggravated the cycle of drought in some areas. Thus, it poses a great threat to crop production. Drought and water shortage have become the limiting factors of world agricultural and social development [5]. The drought resistance of invasive plants is a condition in which the plants undergo a series of adaptive changes in the structure, physiology and biochemistry after they lack the water required for normal growth. Finally, they are concentrated in plant morphology, yield and reproduction. The mechanism of plants coping with water stress environment is complex, and some physiological characteristics comprehensively reflect the drought resistance of plants. In the past three years, domestic research on exotic plants has made great progress [6] [7] [8]. The survey found that there are 108 species of weeds in foreign countries, belonging to 23 families and 76 genera, of which 15 are considered to be national or regional [9]. At present, there are related reports on the factors affecting the germination of Phyllostachys praecox seeds, such as temperature, light, and different soil substrate fertilization [10]. The literature has shown that the distribution of Phyllostachys pubescens [1] has been clear and less. The afferent pathway of Cymbidium Chinese has also been reported. The flowering habits of $S$. chinensis have also been reported. The photosynthetic characteristics of $E$. sinensis have also been studied, but the effects of different soil substrates on the biomass allocation and physiological characteristics of different seedlings under drought conditions have been studied. The study was not involved. At present, people are paying more attention to the harm of safflower and its prevention and control. Moreover, these aspects have not been done so 
far, and we should invest more manpower and material resources to prevent it. In this paper, we studied the effects of drought stress on the biomass allocation and physiological characteristics of Valeriana officinalis seedlings [11], and explored whether it has the possibility of spreading to poor soils, in order to provide theoretical basis and science for the accumulation of basic data of biological characteristics. Based on, and then take reasonable measures to prevent it.

\section{Materials and Methods}

\subsection{Test Materials}

The seeds of the sassafras used in the experiment were collected in October 2014 at the Zhanggutai Institute of Sand Fixing in Fuxin City, Liaoning Province. Source of soil for experiment: Aeolian sandy soil and turf soil in the growth area of Phyllostachys pubescens in the Zhanggutai Institute of Sand Fixation. The soil depth is $0-10 \mathrm{~cm}$, the soil content per pot is $2 \mathrm{~kg}$, the maximum water holding capacity is $17.90 \%$ for aeolian sandy soil, and $22.50 \%$ for peat soil. The sand soil $\mathrm{pH}$ value is 5.60 , the peat soil $\mathrm{pH}$ value is 5.65 ; the aeolian sandy soil organic matter content is $5.70(\mathrm{~g} / \mathrm{kg})$, the total nitrogen content is $0.25(\mathrm{~g} / \mathrm{kg})$, the total phosphorus content is $0.14(\mathrm{~g} / \mathrm{kg})$, and the total potassium content is $15.08(\mathrm{~g})$. $/ \mathrm{kg})$, the organic matter content of peat soil is $7.50(\mathrm{~g} / \mathrm{kg})$, the total nitrogen content is $0.35(\mathrm{~g} / \mathrm{kg})$, the total phosphorus content is $0.08(\mathrm{~g} / \mathrm{kg})$, and the total potassium content is $16.15(\mathrm{~g} / \mathrm{kg})$.

\subsection{Test Methods}

\subsubsection{Effects of Drought Stress on Biomass Allocation of Valeriana officinalis Seedlings}

Seedling growth test: Seedlings with uniform growth of seedlings were transplanted into pots with a diameter of $25 \mathrm{~cm}$ and a height of $20 \mathrm{~cm}$. The soil content of each pot was $2 \mathrm{~kg}$, and 10 seedlings per pot were repeated 4 times. In late June, the soil drought stress test was carried out on the selected 60 pots of normal sorghum seedlings. The soil water content in the basin was reduced by natural evaporation, and the water content was reduced to the extent required by the experiment, and then drought stress began.

Set the water gradient: according to the formula, soil relative water content (weight $\%)=($ original soil weight - dry soil weight $) /$ dry soil weight ${ }^{*} 100 \%$, respectively set as control (CK, soil relative water content is $40 \%$ ), Mild drought stress (W1, 30\%), moderate drought stress (W2, 20\%), and severe drought stress (W3, 10\%) were treated with 4 treatments. Repeat 4 times per treatment level. The stress test lasted for 15 days. When the treatment reached the stress level, the fresh leaves of the experimental seedlings were taken for root biomass, stem biomass, leaf biomass, ear biomass, and total biomass allocation [12].

Determination of biomass of each organ [13]: The plantings of the plant were cut at the mature stage, and the roots of the samples were cut, cleaned, and drained. The samples were separated by roots, stems, leaves, ears and whole 
plants, weighed with an analytical balance (accuracy of $0.0001 \mathrm{~g}$ ), and placed in paper bags and marked.

Fresh plants were collected for 15 minutes in an oven at $105^{\circ} \mathrm{C}$, then placed in a $70^{\circ} \mathrm{C}$ incubator for $2 \mathrm{~h}$ to constant weight, weighed dry, and data was recorded [14].

The biomass of roots, stems, leaves, ears and weights [15] and the proportion of each component to the total biomass of the plants were calculated.

\subsubsection{Determination of the Degree of Mass 0xidation (MDA)}

The malondialdehyde content was determined by the thiobarbituric acid (TBA) method [16]. Weigh $1 \mathrm{~g}$ of the leaves of S. olivaceus, add $2 \mathrm{ml}$ of $10 \%$ trichloroacetic acid (TCA) and a small amount of liquid nitrogen, grind to homogenate, further grind with $8 \mathrm{ml}$ of TCA, transfer the homogenate to a $10 \mathrm{ml}$ centrifuge tube, Centrifuge for $10 \mathrm{~min}$ at $4000 \mathrm{r} \cdot \mathrm{min}^{-1}$, and the supernatant was the extract of the sample. Pipette the supernatant for centrifugation $2 \mathrm{ml} 100$ (control group plus $2 \mathrm{ml}$ distilled water), add $2 \mathrm{ml}$ of $0.6 \%$ thiobarbituric acid (TBA) solution, mix well, add stopper on the test tube, react on the boiling water bath for 15 min, rapidly cool and then centrifuge. The supernatant was taken to determine the optical density at $532 \mathrm{~nm}, 600 \mathrm{~nm}$, and $450 \mathrm{~nm}$.

The concentration of MDA in the extract $\mathrm{C}\left(\mu \mathrm{mol} \cdot \mathrm{L}^{-1}\right)$

$$
\begin{aligned}
= & 6.45\left(\mathrm{OD}_{532}-\mathrm{OD}_{600}\right)-0.56 \mathrm{OD}_{450} \\
& \text { Sample MDA content }\left(\mathrm{nmol} \cdot \mathrm{g}^{-1} \mathrm{FW}\right)=\mathrm{c} \cdot \mathrm{N} \cdot \mathrm{W}^{-1}
\end{aligned}
$$

where $\mathrm{c}$ is MDA concentration $\left(\mu \mathrm{mol} \cdot \mathrm{L}^{-1}\right) ; \mathrm{N}$ is extraction volume $(\mathrm{ml}) ; \mathrm{W}$ is plant tissue fresh weight $(\mathrm{g})$.

\subsubsection{Determination of Relative Water Content of Leaves}

One: There are two ways to express the water content of the tissue: one is based on dry weight; the other is based on fresh weight. Thus divided into dry weight method and fresh weight method;

Tissue water content $($ fresh weight $\%)=(\mathrm{Wf}-\mathrm{Wd}) / \mathrm{Wf} \times 100$

Tissue water content dry weight $\%)=(\mathrm{Wf}-\mathrm{Wd}) / \mathrm{Wd} \times 100$

where Wf: tissue fresh weight; Wd: tissue dry weight.

Plant tissue relative water content (RWC) refers to the percentage of tissue water content to saturated water content: $\mathrm{RWC}=((\mathrm{Wf}-\mathrm{Wd}) /(\mathrm{Wt}-\mathrm{Wd}) \times 100$

where WT: the weight of the tissue after it is fully saturated with water.

Water saturation deficit (WSD) refers to the difference between the actual relative water content of plant tissue and the saturated relative water content (100\%). Commonly used the following formula: WSD = 1 - RWC

In actual measurement, it can be calculated by the following formula:

$$
\mathrm{WSD}=(\mathrm{Wt}-\mathrm{Wf}) /(\mathrm{Wt}-\mathrm{Wd}) \times 100
$$

Two: instruments and appliances: balance (sensing $0.1 \mathrm{mmg}$ ); oven; scissors; 3 $100 \mathrm{ml}$ beaker; 3 aluminum boxes; absorbent paper. 
Three: method

1) Cut the leaves of the plant tissue of the plant, and quickly put it into the aluminum box of known weight and weigh the fresh weight (Wf).

2) Place the plant tissue together with the aluminum box in an oven that has been heated to $105^{\circ} \mathrm{C}$, kill for $15 \mathrm{~min}$, then bake at $80^{\circ} \mathrm{C}$ to constant weight and weigh out the dry weight $(\mathrm{Wd})$.

3) To measure the relative water content, after weighing the fresh weight, immerse the sample in distilled water or wrap it in saturated saturated water for 6 $8 \mathrm{~h}$, remove the surface moisture of the sample with absorbent paper, weigh it, and then immerse the sample in distilled water for $1 \mathrm{~h}$, take out, dry, and weigh until the sample saturation weight is approximate, that is, the sample is saturated with fresh weight (WT); if the time for achieving water saturation is known in advance, the saturated fresh weight can be measured once and then baked. Dry, weigh the dry weight (Wd). The obtained $\mathrm{Wf}, \mathrm{Wd}$, and $\mathrm{WT}$ values were substituted into the formula to calculate the sample water content, relative water content, and water saturation loss.

\subsubsection{Determination of Superoxide Dismutase (SOD) Activity}

Nitrogen blue wow (NBT) method [17]: $0.5 \mathrm{~g}$ of leaves were placed in a pre-cooled mortar, and $2 \mathrm{ml}$ of pre-cooled phosphate buffer (containing $1 \%$ PVP) was ground into a slurry on an ice bath. The slurry was transferred to a centrifuge tube, and then the mortar was washed in portions with $8 \mathrm{ml}$ of extraction buffer, completely transferred to a centrifuge tube, centrifuged at $12,000 \mathrm{~g}$ for $30 \mathrm{~min}$ at $4^{\circ} \mathrm{C}$, and the supernatant was collected and stored at low temperature for use. Transparency well, the test tubes with the same texture are three, and the two are the control tubes, which are always the measuring tubes. Add various reagents according to the following table (note the final addition of riboflavin solution). After mixing, a control tube was placed in the dark, and the other tubes were placed under a $4000 \mathrm{~lx}$ fluorescent lamp for $15 \mathrm{~min}$ (depending on the enzyme activity to adjust the reaction time), and then immediately stopped in the dark. Use the light pipe as a blank reference to zero.

The absorbance of each of the other tubes at $560 \mathrm{~nm}$ was measured. Table 1 is the determination of SOD activity by adding reagent

Table 1. Determination of SOD activity by adding reagent.

\begin{tabular}{cc}
\hline reagent (enzyme) & final concentration (colorimetric) \\
\hline $5 \mathrm{mmol} / \mathrm{L}$ phosphate buffer (pH 7.8) & $13 \mathrm{mmo} / \mathrm{L}$ \\
$130 \mathrm{mmo} / \mathrm{L}$ methionine (MET) solution & $75 \mu \mathrm{mol} / \mathrm{L}$ \\
$750 \mu \mathrm{mol} / \mathrm{L}$ nitroblue tetrazolium (NBT) solution & $10 \mu \mathrm{mol} / \mathrm{L}$ \\
$100 \mu \mathrm{mol} / \mathrm{LNa} 2-\mathrm{EDTA}$ solution & $2 \mu \mathrm{mol} / \mathrm{L}$ \\
$20 \mu \mathrm{mol} / \mathrm{L}$ riboflavin solution & control branch is replaced by buffer \\
enzyme solution & 3.0 \\
total capacity &
\end{tabular}




$$
\text { SOD activity }\left(\mathrm{U} \cdot \mathrm{h}^{-1} \cdot \mathrm{g}^{-1} \mathrm{FW}\right)=\left(\mathrm{OD}_{\mathrm{c}}-\mathrm{OD}_{\mathrm{s}}\right) \times \mathrm{V} \times\left(50 \% \times \mathrm{OD}_{\mathrm{c}} \times \mathrm{V}_{\mathrm{s}} \times \mathrm{t} \times \mathrm{m}\right)^{-1}
$$

where $\mathrm{OD}_{\mathrm{c}}$ is the absorbance value of the reaction mixture of the light control tube; ODs is the absorbance value of the sample tube reaction mixture; $\mathrm{V}$ is the total volume of the sample extract $(\mathrm{ml})$; Vs is the total volume of the sample extract taken during the measurement $(\mathrm{ml}) ; \mathrm{t}$ is the reaction time $(\mathrm{h}) ; \mathrm{m}$ is the sample mass $(\mathrm{g})$.

\subsection{Data Processing}

The experimental data were analyzed by multiple comparisons using SPSS 17.0 data processing software.

\section{Results Analysis}

\subsection{Effects of Drought Stress on Biomass Allocation of Two Soil Cultivars}

The effect of drought stress on biomass allocation of Valeriana officinalis in two soils is shown in Figure 1.

It can be seen from Figure 1 that the biomass allocation of E. sinensis under different drought stress levels is different in the two soil types. Compared with the control plants with soil relative water content of $40 \%$, the root biomass distribution was significantly different with the decrease of soil substrate moisture content, which was characterized by peat soil > aeolian sandy soil, which was controlled as $>$ mild drought stress $>$ moderate Drought stress $>$ Severe drought stress. The soil biomass of the charcoal root was the highest in the control group with $40 \%$ soil moisture content, which was $0.084 \mathrm{~g}$. The soil matrix with higher water content was beneficial to the growth of the roots of the plant.

The effect of Drought Stress on Biomass Distribution of Stem of Syzygium chinensis in Two Soils is shown in Figure 2.

It can be seen from Figure 2 that under different drought stress levels, the biomass distribution of Valeriana officinalis showed peat soil $>$ aeolian sandy soil, and control $>$ mild drought stress $>$ moderate drought stress $>$ severe drought stress, of which soil moisture content was 40 . Under the condition of \% control, the biomass of the stem of the peat soil was the largest, which was $0.17 \mathrm{~g}$. The soil matrix with higher water content was beneficial to the growth of the stem of the

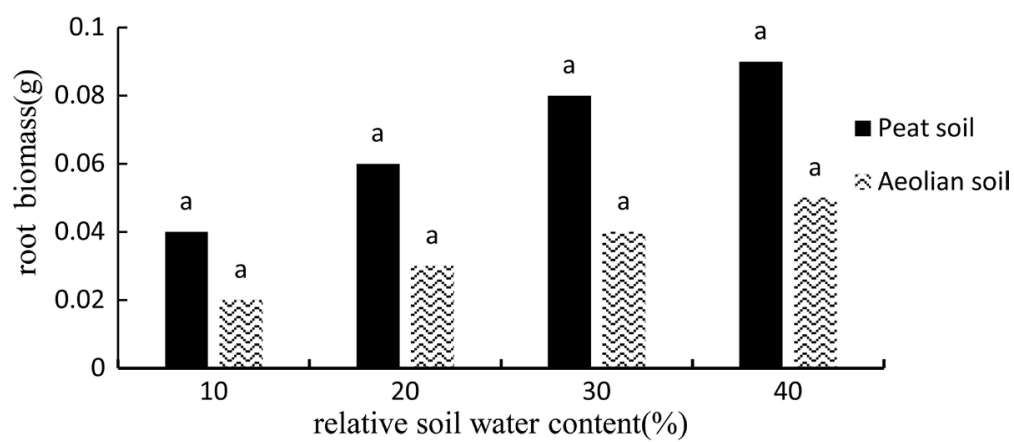

Figure 1. Effect of drought stress on the biomass of roots of the seedlings. 
plant. The effect of drought stress on the biomass allocation of two soil cultivars was as shown in Figure 3.

It can be seen from Figure 3 that under different drought stress levels, the biomass allocation of Valeriana officinalis leaves is represented by peat soil > aeolian sandy soil. As the degree of drought stress deepened, the biomass of leaves of Valeriana officinalis decreased.

The effect of drought stress on the biomass allocation of the two soil cultivars was as shown in Figure 4.

It can be seen from Figure 4 that with the decrease of soil substrate moisture, the biomass allocation is significantly different, and the biomass distribution of ear weight is represented by peat soil $>$ aeolian sandy soil.

The effect of drought stress on the total biomass allocation of two soil-fertilized yarrow grasses is shown in Figure 5.

Based on the significant differences in biomass accumulation of different components of Valeriana officinalis under drought stress, it can be seen from

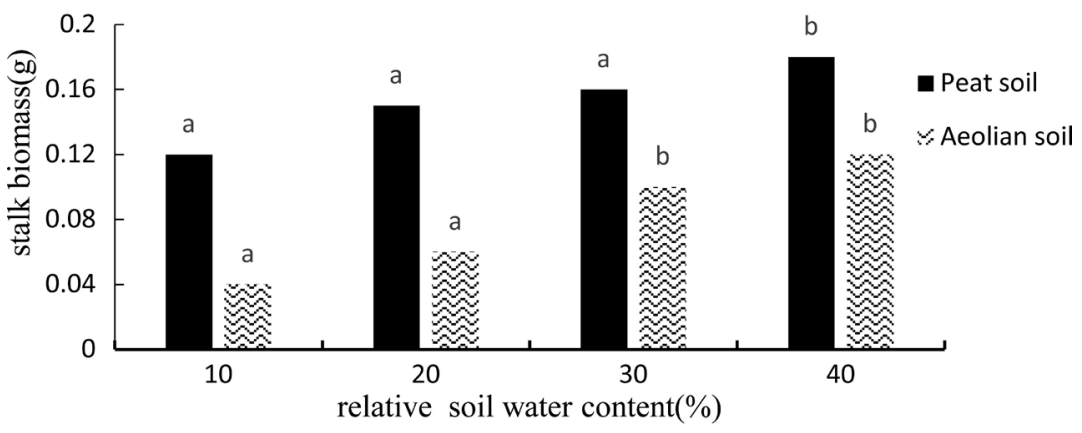

Figure 2. Effect of drought stress on the biomass of stem of the seedlings.

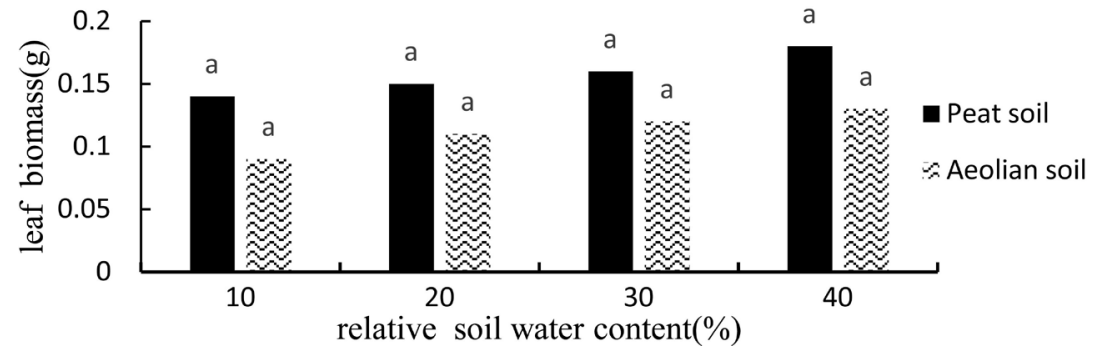

Figure 3. Effect of drought stress on the biomass of blade of the seedlings.

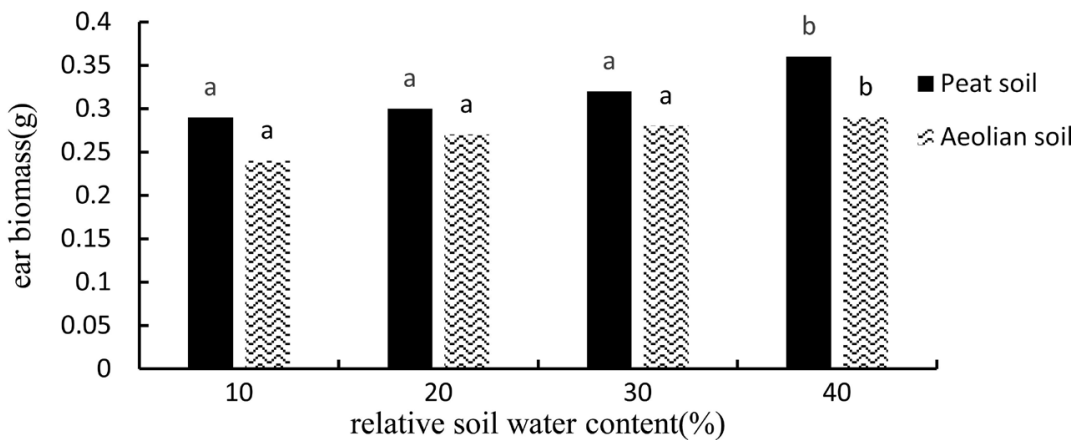

Figure 4. Effect of drought stress on the biomass of spike of the seedlings. 
Figure 5 that under different drought stress, the biomass of different organs of $S$. sinensis is different, and the roots, stems, leaves and ear weights of plants are different. The amount gradually decreased, showing as chart $>$ aeolian sandy soil, and control $>$ mild drought stress $>$ moderate drought stress $>$ severe drought stress, biomass of each organ. The order is: ear $>$ leaf $>$ stem $>$ root, and the alfalfa grass can survive in the aeolian sandy soil with less soil nutrient content. The relative water-bearing high grass soil substrate is beneficial to the growth of the plant.

\subsection{Effects of Drought Stress on the Content of Malondialdehyde in Two Soil-Less Geranium Seedlings}

It can be seen from Figure 6 that the higher the degree of drought, the higher the content of malondialdehyde (MDA) in the seedlings of $P$. humilis in the peat soil. When the relative water content of the soil substrate is $40 \%$, the malondialdehyde content of the $L$. chinensis seedlings begins. As the treatment time prolonged, the malondialdehyde content gradually increased, and the moisture content of each treatment group was 3 days, 6 days, and 9 days, respectively, compared with the control MDA. The above results indicated that the malondialdehyde content of the seedlings did not change much after 6 days of drought treatment; the longer the treatment time, the higher the malondialdehyde content of the young plants.

It can be seen from Figure 7 that the longer the drought degree, the lower the content of malondialdehyde (MDA) in the amaranthus chinensis seedlings decreased first and then increased. With the prolongation of the treatment time, the malondialdehyde content gradually increased. The MDA content increased

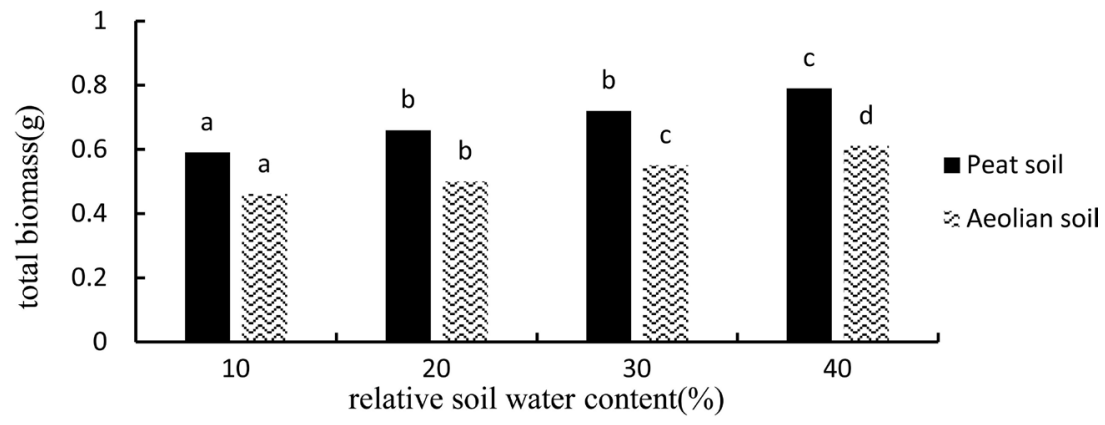

Figure 5. Effect of drought stress on the biomass of total biomass of the seedlings.

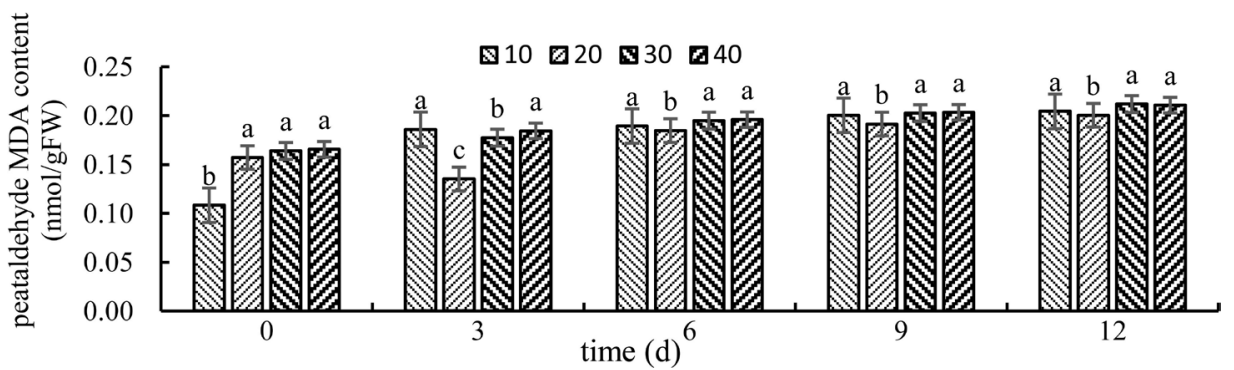

Figure 6. Effect of drought stress on peat soil sandbur MDA content. 
significantly at 3,6, and 9 days compared with the control MDA content. The above results indicated that compared with the control, the content of malondialdehyde in the seedlings was significantly increased at 3 days of drought treatment; the longer the treatment time, the higher the malondialdehyde content of the young plants.

\subsection{Effects of Drought Stress on Relative Water Content of Leaves of $P$. humilis}

It can be seen from Figure 8 that the greater the degree of drought, the lower the relative water content of the young sorghum seedlings in the peat soil, compared with the control, when the relative water content of the soil substrate is $10 \%$ in the drought treatment for 3 days, the sedge The relative water content of the seedlings began to decrease significantly. With the prolongation of treatment time, the relative water content of the leaves decreased gradually. The water content of each treatment group was significantly lower than that of the control at 3, 6, and 9 days. The above results indicated that the relative water content of the seedlings decreased during the three days of drought treatment; the longer the treatment time, the lower the relative water content of the young plants.

\subsection{Effects of Drought Stress on Relative Water Content of $A$. sinensis Leaves}

It can be seen from Figure 9 that the greater the degree of drought, the lower the relative water content of the aeolian sandy soil and the lower the relative water content of the seedlings. Compared with the control, the relative water content

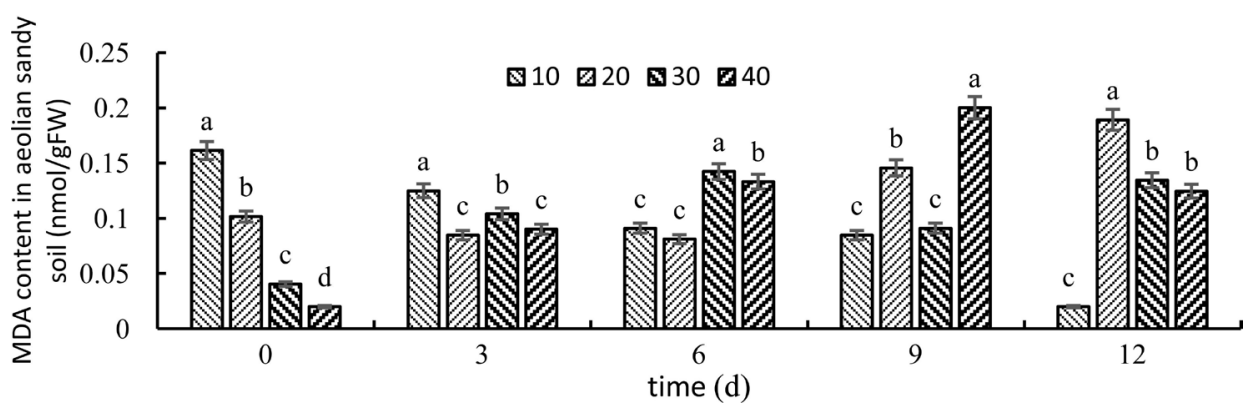

Figure 7. Effects of drought stress on the content of MDA in aeolian sandy soil.

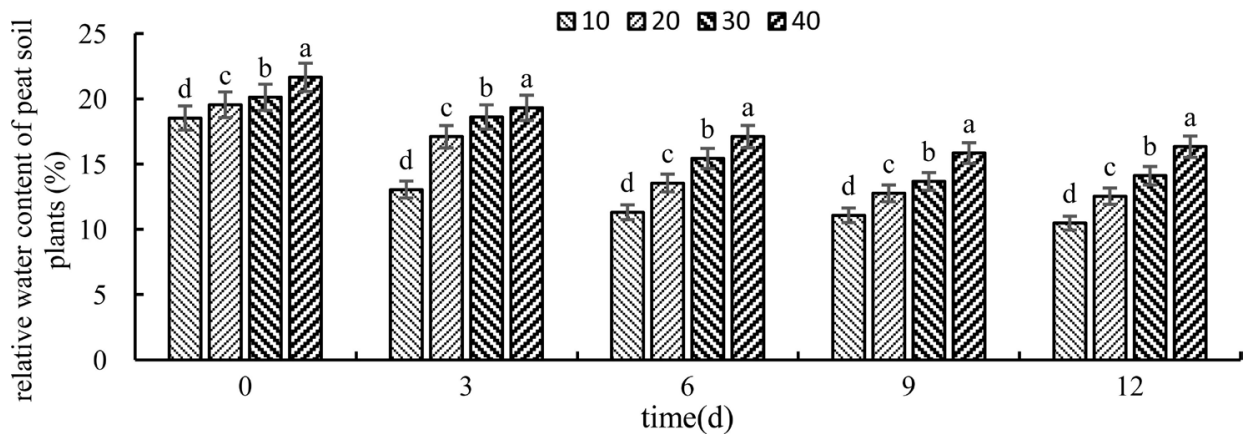

Figure 8. Effect of drought stress on peat soil sandbur relative water content. 
of the leaves gradually increased with the treatment time, and the moisture content of each treatment group increased. At 3 days, 6 days, and 9 days, the relative water content was significantly lower than that of the control, and the relative water content of each aeolian sandy soil treatment group was significantly lower than that of the grass carbon soil group. The above results indicated that the relative water content of the seedlings decreased during the three days of drought treatment; the longer the treatment time, the lower the relative water content of the young plants.

\subsection{Effects of Drought Stress on SOD Activity of Phyllostachys pubescens $\mathrm{L}$.}

It can be seen from Figure 10 that the superoxide gasification enzyme (SOD) activity of the geranium seedlings in the drought stress treatment group in the peat soil matrix was significantly increased, and the difference was significant compared with the control. The SOD activity is expressed as the relative water content of the soil $40 \%>30 \%>20 \%>10 \%$, and the SOD activity gradually increases with the treatment time. The results showed that drought stress significantly increased the SOD activity of the seedlings of Valeriana.

\subsection{Effects of Drought Stress on SOD Activity of $A$. sinica}

It can be seen from Figure 11 that the superoxide gasification enzyme (SOD) activity of the geranium seedlings in the arid sandy soil treatment group was significantly increased, and the difference was significant compared with the control.

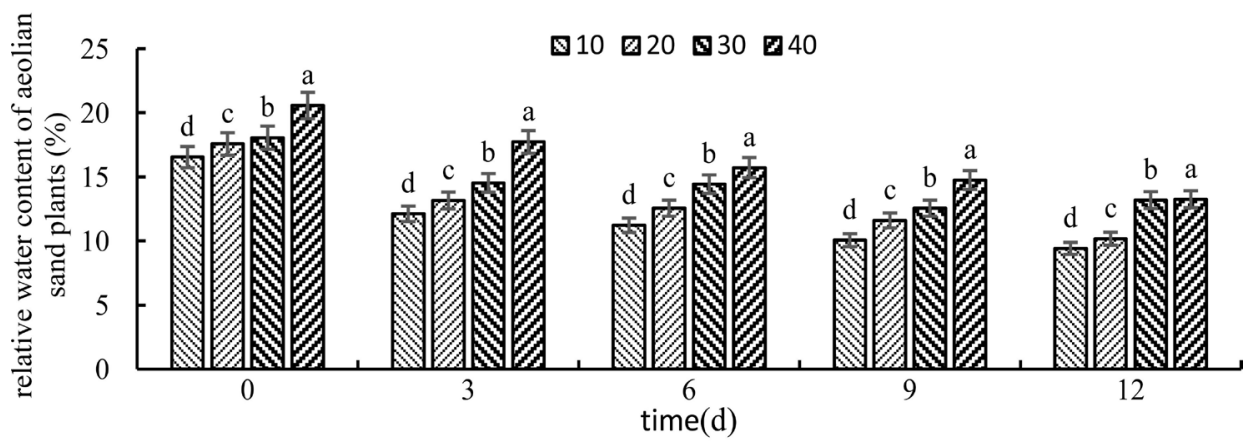

Figure 9. Effects of drought stress on the relative water content of sandy soil.

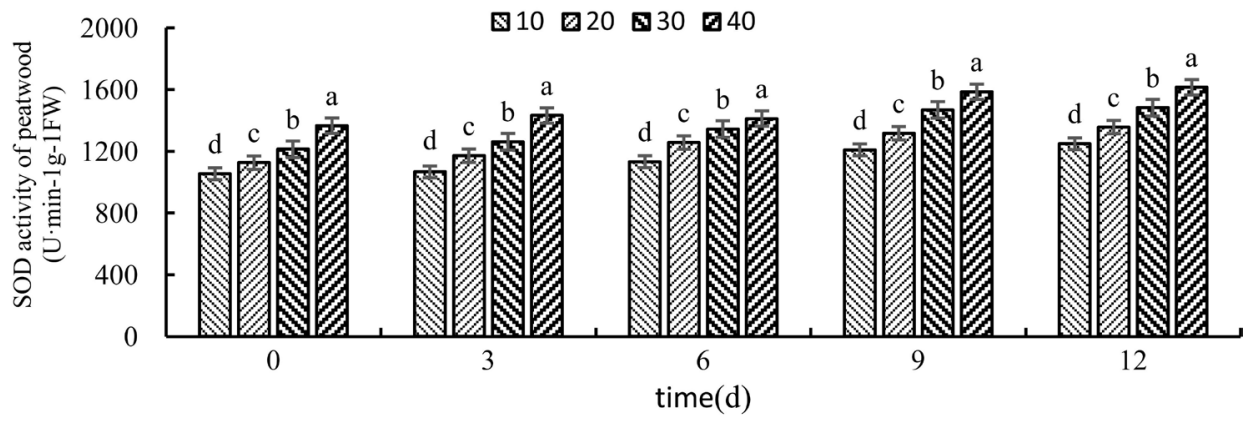

Figure 10. Effect of drought stress on peat soil sandbur SOD activity. 


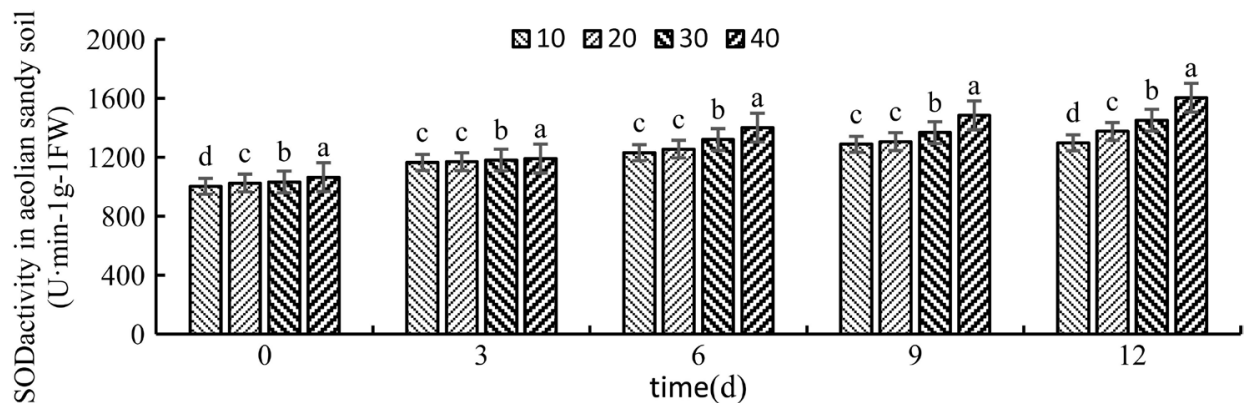

Figure 11. Effects of drought stress on the activity of SOD in aeolian sandy soil.

The specific performance is that the soil relative water content is $40 \%>30 \%>$ $20 \%>10 \%$, and the SOD activity gradually increases with the treatment time. The experimental results show that drought stress significantly increases the SOD activity of the seedlings of Valeriana officinalis

\section{Conclusions and Discussion}

In the aspect of seedling growth, sufficient water is needed in the growth process of seedlings, and the soil moisture content of different soil substrates is different. With the increase of water content, the different soil substrates and the individual plants and the components gradually decrease with each other. The performance is peat soil $>$ wind sand soil. The order of biomass of the organs of the plant was: panicle $>$ leaf $>$ root $>$ stem, and the proportion of biomass in the grassland of different soil substrates was greater than that of underground biomass.

Malondialdehyde is one of the end products of membrane lipid peroxidation, and its content is one of the indicators of the severity of drought stress. Wang Likun et al. studied the effects of drought stress on the growth and physiological and ecological indexes of invasive plants, and the accumulation of malondialdehyde in the leaves of Pseudostellaria sinensis leaves increased with the increase of stress intensity and time [18]. The results of this test are consistent with the results of Wang Likun et al., which indicates that the longer the drought intensity, the greater the damage caused by plant membrane lipids and the more accumulation of reactive oxygen species in the body.

The relative water content of plant leaves [19] is an important indicator of plant tissue water status. Plant tissue water content directly affects plant growth, biomass allocation, physiological metabolic activities and even plant yield. Therefore, the determination of plant tissue water content has important theoretical and practical significance in plant physiology research. The experimental results show that with the increase of the degree of drought stress and the treatment time in the two soil matrices, the relative water content of the seedlings of the sassafras sylvestris decreased gradually, and the peat soil > aeolian sandy soil, thus coping with the adversity surroundings.

In the case of normal growth, the active oxygen produced by the plant can pass through its own antioxidant enzyme system (mainly by SOD). 
The important antioxidant chain in the plant is cleared [20] [21], and the plant's active oxygen content increases under stress, and it has a destructive effect on biological functional molecules such as amino acids, proteins and sugars [22] [23]. SOD is considered to be the first line of defense against biological adverse effects. It catalyzes the disproportionation of superoxide anion radicals to form $\mathrm{H}_{2} \mathrm{O}_{2}$ and $\mathrm{O}_{2}$, preventing superoxide anion radicals from generating hydroxyl radicals [24]. An increase in SOD activity leads to an increase in $\mathrm{H}_{2} \mathrm{O}_{2}$ content, which induces or activates $\mathrm{H}_{2} \mathrm{O}_{2}$ scavenging enzymes, which convert $\mathrm{H}_{2} \mathrm{O}_{2}$ into $\mathrm{H}_{2} \mathrm{O}$ and $\mathrm{O}_{2}$ through different reaction pathways, thereby alleviating cell damage caused by stress [25] [26].

With the extension of time, the SOD of the Phyllostachys pubescens seedlings gradually increased, which affected the growth and development of the sassafras sinensis in the adversity.

\section{Conflicts of Interest}

The authors declare no conflicts of interest regarding the publication of this paper.

\section{References}

[1] Wang, W. and Han, Z.S. (2005) Alien Invasive Biology-Hazard and Distribution of Lesser Flowering Grass in Liaoning Area. Grass Science, No. 7, 21-24.

[2] Qiu, Y., Zhuang, W., Qu, B., et al. (2009) Distribution Status, Existing Problems and Prevention and Control Suggestions of Shaohua Licao in Liaoning Province. Environmental Remediation, No. 3, 284-287.

[3] Wang, P. (2015) Study on the Effects of Shading and Drought Stress on Physiological Indexes and Photosynthetic Characteristics of Lycium barbarum. Liaoning University, Shenyang, 5 .

[4] Qiang, S. and Cao, X.Z. (2000) Investigation and Analysis of Chinese Exotic Weeds. Journal of Plant Resources and Environment, 9, 34-38.

[5] Deng, Z.W., Zhang, Q., Xin, J.W., et al. (2008) Research Progress of Arid Ecological Environment and Water Resources Response to Global Warming. Journal of Glaciology and Geocryology, 30, 57-63.

[6] Zhou, Z.-S., Guo, J.-Y. and Chen, H.-S. (2010) Effect of Humidity on the Development and Fecundity of Ophraella communa (Coleoptera: Chrysomelidae). Bio Control, No. 55, 313-319. https://doi.org/10.1007/s10526-009-9242-9

[7] Song, L.Y., Wu, J.R. and Li, C.H. (2009) Different Responses of Invasive and Native Species to Elevated $\mathrm{CO}_{2} 270$ Concentration. Acta Oecologica, 35, 128-135. https://doi.org/10.1016/j.actao.2008.09.002

[8] Huang, W., Siemann, E. and Wheeler, G.S. (2010) Resource Allocation to Defence and Growth Are Driven by Different Responses to Generalist and Specialist Herbivory in an Invasive Plant. Journal of Ecology, 98, 1157-1167.

https://doi.org/10.1111/j.1365-2745.2010.01704.x

[9] Qu, B., Zhu, M.X., Wang, W., et al. (2011) Effects of Four Environmental Factors on Seed Germination of Cenchrus pauciflorus Benth. Seed, 3, 277-278.

[10] Li, Y. (2006) Effects of Drought Stress on Osmotic Adjustment Substances in Nan- 
dina Domestica in Different Soil Types. Southwest University, Chongqing.

[11] Zhang, Z.X. and Tian, X. (2011) Characteristics of Biomass Distribution of Ramets under Drought and Irrigation Conditions. Grass Science, No. 2, 18-20.

[12] Wang, K.F., Ji, M.S., Li, Y., et al. (2015) Study on Seed Germination and Seedling Growth Characteristics of Valeriana officinalis. Journal of Jiangxi Agricultural University, 37, 997-1004.

[13] Jia, C.L., Li, Q.F. and Xu, J. (2012) Study on Flowering and Fruiting Characteristics of Alien Invasive Plant Light-Stalked Sorghum. Journal of Inner Mongolia Agricultural University, 2, 255-260.

[14] Zhou, L.Y., Liu, H.Y., Gao, H.M., et al. (2012) Study on Growth Characteristics of Eucalyptus urophylla during the Whole Growth Period. Journal of Inner Mongolia University for Nationalities (Natural Science Edition), 27.

[15] Yang, L., Han, Z.M., Yang, L.M., et al. (2010) Effects of Water Stress on Photosynthesis, Biomass and Medicinal Materials Quality. Chinese Journal of Applied Ecology, 21, 2523-2528.

[16] Hu, F. and Kong, C.H. (1997) The Allelopathic Effect of the Water-Soluble Substance in the Research of Shenghong and Its Isolation and Identification of Allelochemicals. Chinese Journal of Applied Ecology, No. 8, 304-308.

[17] Muller, C.H., Muller, W.H. and Haines, B.L. (1964) Volatile Growth Inhibitors Production by Shrubs. Science, 143, 471-473. https://doi.org/10.1126/science.143.3605.471

[18] Kan, L.Y., Xie, G.S. and Wang, J.K. (2009) Effects of Drought Stress on the Growth and Physiological and Ecological Indexes of Invasive Plants of Pseudomonas sinensis. Chinese Journal of Tropical Crops, 30, 608-612.

[19] Zhang, X.W., Liu, Y.X., Liu, W.X., et al. (2007) Plant Allelopathic Substances and Their Release Pathways. Chinese Agricultural Science Bulletin, 23, 295-297.

[20] Yang, G.Q. and Wan, F.H. (2008) Influence of Two Allelochemicals from Ageratina adenophora Sprengel on ABA, IAA and ZR Contents in Roots of Uplandrice Seedlings. Allelopathy Journal, 21, 253-262.

[21] Bohm, P.A.F. and Zanardo, F.M.L. (2006) Peroxidase Activity and Lignification in Soybean Root Growth-Inhibition by Juglone. Biologia Plantarum, 50, 315-317. https://doi.org/10.1007/s10535-006-0029-x

[22] Li, F.M. and Hu, M.Y. (2005) Isolation and Characterization of a Novel Antialgal Allelochemical from Phragmites Communis. Applied and Environmental Microbiology, 71, 6545-6553. https://doi.org/10.1128/AEM.71.11.6545-6553.2005

[23] Yang, Y.H., Wan, H., Liao, F.L., et al. (2005) Effects of Plant Allelochemicals on Seed Germination. Journal of Ecology, 24, 1459-1465.

[24] Parra, M., Anaya, A.L., Espinosa, F., et al. (1981) Allelopathic Potential of Piqueria trinervia (Compositae) and Piquerols A and B. Journal of Chemical Ecology, 7, 509-515. https://doi.org/10.1007/BF00987699

[25] Yu, J.Q., Ye, S.F. and Zhang, M.F. (2003) Effects of Root Exudates and Aqueous Root Extracts of Cucumber (Cucumis sativus) and Allelochemicals, on Photosynthesis and Antioxidant Enzymes in Cucumber. Biochemical Systematics and Ecolo$g y, 31,129-139$. https://doi.org/10.1016/S0305-1978(02)00150-3

[26] Guo, H.M. and Pei, X.X. (2011) Molecular Cloning of Allelopathy Related Genes and Their Relation to HHO in Eupatorium Adenophorum. Molecular Biology Reports, 38, 4651-4656. https://doi.org/10.1007/s11033-010-0599-8 